\title{
The changing pattern of foreign trade specialization in Indian manufacturing
}

\author{
Michele Alessandrini,* Bassam Fattouh,,* and Pasquale \\ Scaramozzino***
}

\begin{abstract}
This paper examines the pattern of international trade specialization in Indian manufacturing since the mid-1980s by using data on trade flows. Low-technology sectors still dominate the categories for which India exhibits the largest degree of trade specialization. By contrast, high-technology sectors are prevalent among the categories for which India is import-dependent. Significantly, India has experienced an improvement in the degree of specialization in some of the most dynamic sectors of world trade.
\end{abstract}

Key words: India, trade specialization, manufacturing, Lafay index

JEL classification: F14, O14, O24, O53

\section{Introduction}

The high and sustained rate of growth of the Indian economy in recent decades and the spectacular performance of some of its technologically advanced service industries have attracted considerable attention among economists. It has been argued that India may be able to leapfrog the traditional pattern of development, according to which resources are first transferred from the agricultural to the manufacturing sector. India is experiencing a rapid growth in the service sector, apparently without going through the intermediate phase of a significant expansion of manufacturing.

*Università di Roma ‘Tor Vergata', e-mail: m.alessandrini@hotmail.com

**SOAS, University of London, e-mail: bf11@soas.ac.uk

*** Università di Roma 'Tor Vergata' and SOAS, University of London, e-mail: ps6@soas.ac.uk

We are extremely grateful to Andrew Glyn and Andrea Zaghini for very generous suggestions and advice, to Benno Ferrarini for his kind help with the data, and to Barbara Annicchiarico, Daniel Gustafson, Yasmeen Khwaja, Salvatore Morelli, Beniamino Quintieri, Massimo Sbracia, and an anonymous referee for very helpful comments. We remain responsible for any mistakes. doi: $10.1093 / \mathrm{icb} / \mathrm{grm} 013$

(C) The Authors 2007. Published by Oxford University Press.

For permissions please e-mail: journals.permissions@oxfordjournals.org 
At the same time, despite the opening up of trade since the reforms of the 1980s and 1990s, India can still be regarded as a relatively closed economy (Cerra et al., 2005; Schiff, 2005). In 2005 , it accounted for only about $1 \frac{1}{2}$ per cent of the global trade in good and services. Its share of intra-industry trade is also relatively modest. There could, therefore, be untapped potential for growth from further expansion of its trade with the rest of the world. This effect could be enhanced by the positive gain in efficiency for firms from international exposure. Alcalà and Ciccone (2004) find a positive correlation between openness and total factor productivity, mainly through trade and scale effects. For India, Krishna and Mitra (1998) and Topalova (2004) found that the lowering of trade restrictions had a positive impact on firm-level productivity, while Tucci (2005) shows that firms that are engaged in export and import activities display higher productivity than the firms that are not.

The debate on the potential gains to India from international trade often tends to look at whether the sectors that are experiencing a rapid growth in trade are also more likely to bring employment benefits to the country in terms of their labour-intensive content. Kochhar et al. (2006), for instance, specifically look at the role of the policies adopted after India's independence in promoting skill-intensive manufacturing, such as the creation of industries producing capital goods and the relatively large investment on higher education (see also Banerjee, 2006).

This paper considers the pattern of foreign trade specialization in India since the mid1980s, when the early economic reforms by Rajiv Gandhi were implemented. In our view, the vast diversity in education and skills in the Indian labour force, and the extreme variety in technological content across sectors, warrant a detailed analysis of the sources of comparative advantage across the production sectors. Indeed, some recent literature on endogenous growth has argued that the long-term growth potential of an economy can be positively related to its specialization in technologically advanced sectors (Young, 1991; Grossman and Helpman, 1991; Lall, 1992).

We mainly concentrate our attention on the export and import performance of three-digit industries in the manufacturing sector. The focus on the manufacturing sector is motivated by the consideration that, since the 1980s, growth has been driven by states with a higher level of manufacturing activity (Rodrik and Subramanian, 2004). A strong manufacturing sector appears, thus, to be an important condition for development.

The measure of trade specialization used in this paper is Lafay's index (Lafay, 1992), which does not just look at exports, but also considers the size of the intra-industry trade. We examine the pattern of specialization in the last couple of decades and discuss the changes that have occurred during this period. In particular, we explore whether there has been a significant shift in the pattern of specialization towards those sectors that have experienced the fastest growth in world demand. This would signal that trade specialization in India has improved precisely among those sectors that could bring the largest benefits to the economy, in terms of their export potential.

Our main findings confirm some recent concerns about the quality of the pattern of specialization of Indian trade. The sectors in which India specializes still tend to be characterized by a relatively low technological content. Furthermore, the manufacturing sectors in which India does not specialize tend on average to possess a high technological content. This could limit the potential for trade to generate positive technological externalities. On the other hand, there is increasing evidence of specialization in a number of selected high-tech sectors. Furthermore, India's index of specialization has increased precisely in those sectors that have exhibited the fastest growth in world demand, and could therefore be regarded as the most dynamic sectors in world trade. 
The structure of the paper is as follows. Section II looks at the main stylized facts of trade flows since the mid-1980s. Section III considers the role of the service sector and its relationship with manufacturing. Section IV examines the pattern of trade specialization in the Indian manufacturing sector according to the Lafay index. Section V explores the changes in the pattern of specialization across sectors, whereas section VI provides evidence on the dynamics of comparative advantages and world demand. Section VII draws some conclusions.

\section{Foreign trade in India}

The process of globalization which started in the early 1980s has seen a rapid increase in the process of economic integration and in the volume of international trade, which has expanded threefold during the last couple of decades (UNCTAD, 2005). Less developed countries (LDCs) have played an active role in the expansion of world trade and, indeed, the opening up to trade has often constituted one of the key aspects of their growth strategy.

In this context, India was a relative newcomer to the process of expansion of trade, since its opening up to world trade only began after the crisis in 1991. However, the Indian economy had already experienced an acceleration in its rate of growth during the 1980s, as shown by DeLong (2004), Panagariya (2004), and Rodrik and Subramanian (2004). The opening up to international trade should be seen as a crucial aspect of the new approach to economic policy, and as an integral part of the programme of reform.

In this respect, the year 1991 marked a watershed between the pro-business orientation of the Indian government during the 1980s and the pro-market orientation that became prevalent during the 1990s (Rodrik and Subramanian, 2004; Kohli, 2006a,b). The former approach sought to increase the productivity and the profitability of the existing industrial and commercial establishments. This tended to favour incumbent producers and businesses, by protecting them from foreign competition and by promoting the modernization of existing domestic establishments and the creation of new ones. This strategy, initially proposed by Indira Gandhi and implemented by Rajiv Gandhi during the second half of the 1980s, was essentially based on the simplification of the complex system of licences required for production, and, in particular, of those regarding investment and product diversification. These initiatives were mainly targeted on large firms, as confirmed by the reduction in 1985 of a number of restrictions on monopolies that were contained in the Monopolies and Restrictive Trade Practices Act (MRTP). The government of Rajiv Gandhi also introduced some measures of external liberalization, for instance the expansion of the Open General Licensing (OGL), that includes the list of commodities for which no formal licence was required for foreign trade. ${ }^{1}$ The number of commodities for which the government has monopoly rights for imports declined (the so-called 'canalized' imports) and several incentives to export were introduced. Furthermore, the rupee experienced a real depreciation by about 30 per cent. It is important to note that these measures were mainly directed to intermediate and capital goods. Consumption goods remained highly protected throughout the decade. A significant exception is medicinal and pharmaceutical products (Das, 2003, Table 5), a sector that was to experience a very rapid growth during the following decade.

\footnotetext{
${ }^{1}$ The OGL was reintroduced in 1976 when it only listed 79 products. By 1988 it already included 1,170 capital goods and 949 intermediate goods (Panagariya, 2004).
} 
By contrast, the pro-market orientation of the 1990s sought to pursue economic liberalization with the aim of removing impediments to markets. The previous initiatives towards liberalization and the removal of the system of licences were intensified. However, the main aim of the strategy was now decisively shifted to give a high priority to the lowering of the barriers to trade and to the enhancement of international integration. Tariff and non-tariff barriers were reduced for most intermediate and capital goods, even in those sectors that were more heavily protected during the 1980s, such as iron and steel. Some sectors remained canalized: these included fertilizers and pesticides and selected sectors of strategic importance, such as petroleum products and those sectors related to national security and defence. Consumption goods were only liberalized starting from 2001. During the 1990s, many sectors, including leather, remained under a licence regime. By contrast, medicinal and pharmaceutical products, together with cotton fabrics, followed the trend of the 1980s and were already free of restrictions by the mid-1990s.

Numerous initiatives were also put in place to attract foreign capital, especially in services. Banking, telecommunications, and infrastructure, where the Indian state sector was operating under conditions of monopoly, were opened to the private sector and to foreign direct investment (FDI). In information technology (IT), in particular, the share of foreign investment in units dedicated to exports was allowed to reach 100 per cent (Panagariya, 2004). These units can be established under a number of possible schemes, including Export Oriented Units (EOUs), Export Processing Zones (EPZs), Special Economic Zones (SEZs), Software Technology Parks (STPs), and Electronics Hardware Technology Parks (EHTPs).

Despite India still being a relatively closed country when compared to other developing economies, ${ }^{2}$ the reforms implemented in the 1990 s have enabled the country to abandon the policy of import substitution that had characterized the previous decades and to adopt a clear market-oriented approach. This fundamental shift in policy, that made it possible to face the challenges posed by international integration, is apparent from the analysis of a number of trade figures.

A first important consequence of liberalization was the increase in the degree of openness of the Indian economy. The sum of exports and imports, which never exceeded 15 per cent of GDP throughout the 1980s, had more than doubled during the last few years, exceeding 30 per cent in 2002. This ratio is, however, still lower than that for other LDCs. In China, for instance, total trade to GDP increased from 24 per cent in 1985 to 47.7 per cent in 2002. To put these figures in perspective, the openness ratio for the USA exhibited a modest upward trend and increased from 17 per cent in 1985 to 23 per cent in 2002, whereas for the UK the ratio was well over 55 per cent during most of the period (World Bank, 2006). India's share of world exports also increased, from 0.5 per cent in 1985 to 0.8 per cent in 2002, whereas the share of world imports has also marginally increased from 0.8 per cent in 1985 to 0.9 per cent in 2002 (WTA, 2004). ${ }^{3}$

A second important change that occurred during the 1990s concerns the direction of trade flows, especially regarding exports. In the beginning of the 1990 s the main trading partner for India was Europe, which attracted in excess of 30 per cent of exports (Figure 1). By the beginning of the new millennium the main area of destination for Indian exports was Asia,

\footnotetext{
${ }^{2}$ According to Kohli (2006b, p. 1361): 'By India's own past standards, the changes were quite dramatic. In a comparative and global perspective, however, India's opening to the world remains relatively modest.' See also Ahluwalia (2002) and Kohli (2006a).

${ }^{3}$ By contrast, the share of exports had actually declined from 2.2 per cent to 0.5 per cent between 1948 and 1985 (WTO, 2001).
} 
Figure 1: Destination of Indian exports by area

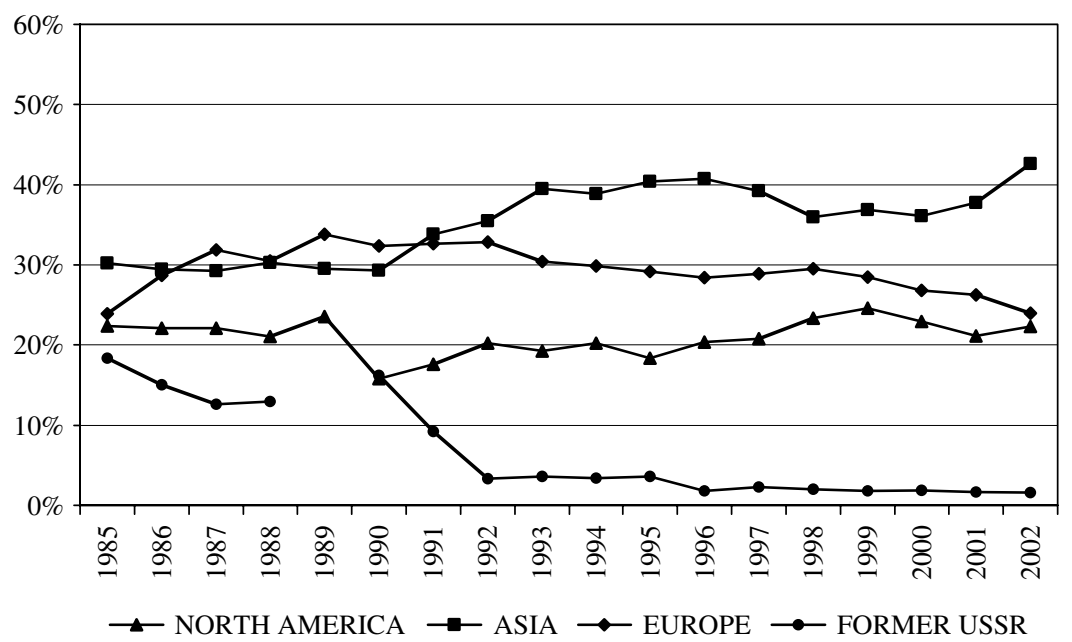

Source: Statistics Canada (2004) (1989 not available for former USSR).

with over 40 per cent of exports. By contrast, the share of Europe declined to 24 per cent by 2002. The share of exports towards North America also increased by about 7 percentage points during the 1990s. In this context, it is important to consider the collapse of trade with the former Soviet Union countries, which used to attract about 18 per cent of Indian products in the mid-1980s. In 2002, the corresponding share was only 1.5 per cent.

A similar pattern emerges for Indian imports (Figure 2). Import flows from Asia increased, whereas those from Europe declined. Contrary to the trend for exports, imports from North America actually declined by about three percentage points.

Figure 2: Source of Indian imports by area

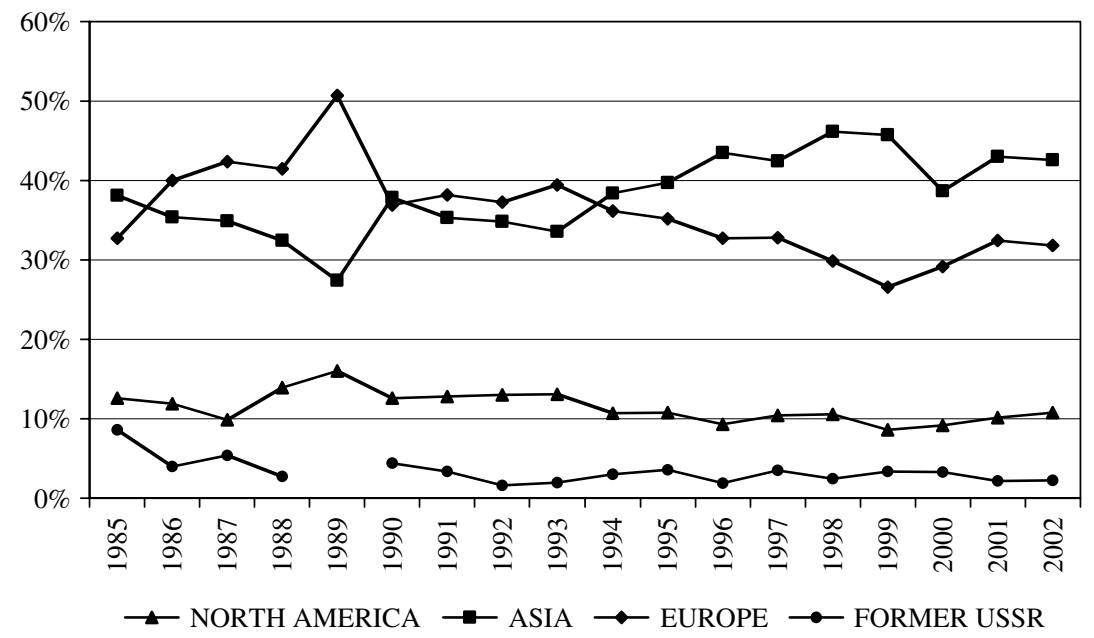

Source: Statistics Canada (2004) (1989 not available for former USSR). 
Table 1: Structure of exports and imports, 1985-2002 (percentages)

\begin{tabular}{lrrrr}
\hline & 1985 & 1990 & 1995 & 2002 \\
\hline Exports & & & & \\
Agricultural raw materials (2 excl. 22, 27, 28) & 2.8 & 4.0 & 1.3 & 1.1 \\
All food items (0, 1, 22, 4) & 25.2 & 15.4 & 18.5 & 12.2 \\
Fuels (3) & 6.0 & 2.9 & 1.7 & 5.1 \\
Manufactured goods (5, 6,7, 8 excl. 68) & 58.2 & 69.9 & 73.3 & 75.0 \\
$\quad$ 5-Chemicals and related products, n.e.s. & 3.6 & 7.4 & 8.1 & 11.1 \\
6-Manufactured goods classified chiefly (excl.68) & 33.7 & 36.8 & 38.6 & 37.3 \\
$\quad$ 7-Machinery and transport equipment & 6.2 & 7.3 & 7.4 & 8.2 \\
$\quad$ 8-Miscellaneous manufactured articles & 14.6 & 18.4 & 19.2 & 18.4 \\
Ores and metals (27, 28, 68) & 7.6 & 5.7 & 3.6 & 4.3 \\
Imports & & & & \\
Agricultural raw materials (2 excl. 22, 27, 28) & 3.0 & 3.4 & 3.7 & 2.9 \\
All food items (0, 1, 22, 4) & 8.4 & 3.4 & 4.3 & 5.7 \\
Fuels (3) & 25.4 & 27.0 & 22.5 & 32.3 \\
Manufactured goods (5, 6,7, 8 excl. 68) & 56.7 & 54.6 & 61.7 & 52.6 \\
$\quad$ 5-Chemicals and related products, n.e.s. & 13.9 & 11.9 & 14.9 & 9.1 \\
6-Manufactured goods classified chiefly (excl.68) & 15.9 & 17.7 & 18.1 & 17.2 \\
7-Machinery and transport equipment & 23.5 & 20.8 & 24.3 & 20.6 \\
8-Miscellaneous manufactured articles & 3.4 & 4.1 & 4.4 & 5.8 \\
Ores and metals (27, 28, 68) & 5.6 & 7.4 & 6.6 & 4.5 \\
\hline
\end{tabular}

Note: n.e.s. is 'not elsewhere specified'.

Source: Statistics Canada (2004) (sectors are classified according to UNCTAD (2005)).

A third important feature of the opening of trade is represented by changes in the structure of trade in goods (Table1). The share of agriculture-based products has declined, mainly to the advantage of manufacturing products. This change is especially noticeable for exports, where the share of manufactured goods had increased to 75 per cent by 2002 . Within manufacturing, the increase in the share of chemicals and related products is especially remarkable, while the share of textiles is fairly stable (sector 65). Regarding imports, there are not large changes on the whole. India had already achieved food independence by the late $1970 \mathrm{~s}$ when, thanks to the Green Revolution, the share of food products had declined from 25 per cent to about 10 per cent of imports. During the 1990s about one-quarter of imports was accounted for by fuels, whose share exceeded 32 per cent in 2002. This figure reflects the large increase in demand for energy owing to the sustained rate of growth of the economy. Within manufacturing, the share of chemicals and related products declined (in parallel with the increase in exports) and the share of sector 7 (machine and transport equipment) remained largely unchanged, but there was a large increase in sectors 75 (office machines and automatic data processing) and 76 (telecommunications and sound-recording apparatus), both linked to IT, and in sector 77 (electrical machinery, apparatus, and appliance).

Finally, the last important consequence of trade liberalization is the increase in FDI. In the late 1980s, FDI amounted to about 0.07 per cent of GDP. By 2002, its share had increased to 0.6 per cent of GDP (World Bank, 2006). Furthermore, the sectoral composition of FDI changed significantly over this period. During the 1980 s, about 85 per cent of FDI was concentrated in the secondary sector, with the chemical sector accounting for about one-third, and with only 5 per cent going into the service sector. By contrast, during the 1990 s the service sector attracted the largest share of FDI (more than 58 per cent on average). The sectors that have benefited the most from FDI are power generation and telecommunications 
(Sharma, 2000). Directly related to the FDI in the service sector is the rapid growth of the IT sector. In 2000, about 21 per cent of world exports of IT services originated in India, which by then had become the largest IT exporting country (Chauvin and Lemoine, 2003). ${ }^{4}$

\section{Manufacturing, services, and growth}

The debate on the performance of the Indian economy and on its growth potential often tends to emphasize the role played by the service sector. The latter has grown at very fast rates during the past couple of decades, and this trend is expected to be maintained over the foreseeable future. The most dynamic components of the service sectors are IT and IT-enabled business services (ITES), whose exports were projected to grow at a rate of about 32-33 per cent during 2005/6 (NASSCOM, 2006). The development of high-tech services is also regarded as critical for facilitating the technology transfers associated with the return migration of highly qualified Indian scientists who had previously migrated abroad and who are bringing back their knowledge and expertise (Arora and Gambardella, 2004; Commander et al., 2004), as well as for the financing of ventures in IT-ITES by members of the Indian diaspora (Saxenian, 2002).

Table 2 shows that the share of services in India's trade has increased during the last few years. The share of services out of total exports increased from around 21 per cent in 1990 to more than 28 per cent in 2002. Quite interestingly, the share of services out of total imports has also witnessed similar growth, increasing from 20.5 per cent in 1990 to 27 per cent in 2002.

The service sector has overtaken industry in terms of both value added and employment. The share of value added of the manufacturing sector on GDP amounted to 16.3 per cent in 1980 and to 15.9 per cent in 2000 (Kochhar et al., 2006). By contrast, the value added share of services on GDP increased from 36.6 per cent in 1980 to 48.8 per cent in 2000 . The shares of employment, however, tell a somewhat different story, with an increase in both manufacturing (from 13.9 per cent in 1980 to 18.2 per cent in 2000) and services (from 18.6 per cent to 22.4 per cent). The increase in employment was comparatively stronger for manufacturing. Thus, it might appear that the manufacturing sector could still play a significant role in job creation.

Table 2: Share of trade in services out of total exports and imports (\%)

\begin{tabular}{lcccc}
\hline & 1990 & 1995 & $\mathbf{2 0 0 0}$ & $\mathbf{2 0 0 2}$ \\
\hline $\begin{array}{l}\text { Exports } \\
\text { Services share }\end{array}$ & 20.47 & 18.11 & 28.25 & 28.34 \\
Goods share & 79.53 & 81.89 & 71.75 & 71.66 \\
$\begin{array}{l}\text { Imports } \\
\text { Services share }\end{array}$ & 20.53 & 22.83 & 27.13 & 27.13 \\
Goods share & 79.47 & 77.17 & 72.87 & 72.87 \\
\hline
\end{tabular}

Source: UNCTAD (2005).

\footnotetext{
${ }^{4}$ See Patibandla and Petersen (2002) for a discussion of the role of transnational corporations in stimulating the growth of the software industry.
} 
More generally, it is important to determine whether it is conceivable that the Indian economy might follow an unconventional pattern of development, whereby the intermediate phase of industrialization is passed over and the economy directly transforms from being prevalently agricultural to being mainly based on the service sector. According to the influential Kaldorian analysis of development, industrialization is a necessary stage of development, since the industrial sector represents the key for growth (in Kaldor's own words, 'the kind of economic growth which involves the use of modern technology and which eventuates in high real income per capita is inconceivable without industrialization' (Kaldor, 1967, p. 54)). High-productivity agriculture cannot employ more than a fraction of the available labour force. The establishment of domestic industries is, thus, essential for productivity improvements and for the realization of learning-by-doing and increasing returns associated with product differentiation, new processes, and new subsidiary industries.

There is, however, a debate about whether services might replace industry as an engine of growth, in the light of the recent technological developments and of the changing nature of many service activities. It is argued, for instance, that IT could lead to even greater spillovers than manufacturing. Dasgupta and Singh $(2005,2006)$ specifically examine the role of manufacturing versus services in LDCs, with particular regard to India. Their empirical evidence is supportive of the view that both manufacturing and services can act as engines of growth for the Indian economy. They argue that high-tech information and communication technology (ITC) services, in particular, can be regarded as dynamic sectors in Kaldor's sense and can thus be instrumental for growth.

Rowthorn (2006) considers that the strength of India in IT activities has a number of advantages, both in terms of their direct contribution to exports and growth and as a complement and stimulus to other activities. Rowthorn also examines the potential changes to the structure of comparative advantage that can emerge as a result of the relative increase in productivity in 'knowledge-intensive' goods and services as compared to 'labour-intensive' ones, as well as of the relative pattern of earnings for educated and uneducated workers. A possible implication is that the relative pay of uneducated workers may increase in the future as compared to the pay of educated workers, which would trigger changes in the relative supply of skilled versus unskilled labour. In the long run, this could lead to an increase in the relative cost of labour-intensive products and to a rise in their price relative to knowledge-intensive items. India's comparative advantage may, therefore, shift towards more sophisticated export activities.

The analysis of manufacturing and services is also the object of the investigation of India's pattern of development by Kochhar et al. (2006). They control for GDP per capita and for country size in cross-country regressions on shares of output and employment in order to assess the specific role of manufacturing. They find that, in the early 1980 s, the India dummy attracted a positive but statistically insignificant coefficient in manufacturing and a negative coefficient in services, both for output and employment. Hence, India was a negative outlier in services vis à vis countries that were comparable for income and size. In 2000, India was still not an outlier for its shares of output and employment in manufacturing, but it was now a positive outlier for output and a negative outlier for employment in services. These findings reflect the extremely large increase in productivity that took place in the service sector, but, at the same time, raise concerns about the low elasticity of the demand for labour in the service sector and the possibility of jobless growth (concerns already present in Dasgupta and Singh (2005)).

A very informative analysis of the relative role of manufacturing and services in Indian growth at the state level has been carried out by Rodrik and Subramanian (2004). They 
examine the effect on the state growth rate of the share of registered manufacturing in total output. After introducing a number of controls, they find that the manufacturing shares had a positive and significant effect on state growth during the 1980s and the 1990s. ${ }^{5}$ Hence, the presence of a strong manufacturing sector can be an important determinant of the different growth performances across Indian states, despite the growing importance of the service sector. Manufacturing activities can still be regarded as a critical engine of growth for the economy. The development of manufacturing might also be crucial in order to allow India to expand supply and reduce the risk that the current growth spurt might be unsustainable because of supply-side and capacity constraints (The Economist, 2007). It would, therefore, appear that a detailed examination of the pattern of trade specialization in the manufacturing sector is essential in order to assess the growth potential of the Indian economy.

\section{Trade specialization}

The literature suggests a large number of indicators to measure the comparative advantage of different countries. A widely used indicator is the Revealed Comparative Advantage $(R C A)$ index proposed by Balassa (1965). This indicator compares the national export structure with that of the world and thus focuses only on export data. However, in the current context of increasing intra-industry trade, any indicator that just focuses on exports is likely to throw out valuable information, especially if the analysis is carried out at a high level of disaggregation.

Thus, instead of relying on the $R C A$, we base our analysis on the Lafay index. Rather than just looking at exports, the Lafay index also includes imports and thus is able to capture intra-industry trade flows. Another advantage of the Lafay measure is that it is able to control for distortions due to the business cycle (Lafay, 1992). We construct the following Lafay index $(L F I)$ for India ${ }^{6}$

$$
L F I_{j}=100\left(\frac{x_{j}-m_{j}}{x_{j}+m_{j}}-\frac{\sum_{j=1}^{N}\left(x_{j}-m_{j}\right)}{\sum_{j=1}^{N}\left(x_{j}+m_{j}\right)}\right) \frac{x_{j}+m_{j}}{\sum_{j=1}^{N}\left(x_{j}+m_{j}\right)}
$$

where $x_{j}$ is Indian exports of product $j$ towards the rest of the world, $m_{j}$ is imports from the rest of the world towards India, and $N$ is the number of traded goods. According to the above formula, the comparative advantage for India in product $j$ is the deviation of the product $j$ normalized trade balance from the overall normalized balanced trade. Thus, the sum of $L F I$ across $j$ for any year must by construction be equal to zero. Positive values of the $L F I$ imply specialization and higher values of the $L F I$ imply higher degrees of specialization, with the sector making a bigger contribution to the trade balance. On the other hand, negative values imply reliance on imports. One possible shortcoming of the index is that it may take a value close to zero for a sector in which India is both an importer and an exporter of equivalent

\footnotetext{
${ }^{5}$ Interestingly, the share of manufacturing had an insignificant effect during the 1960s and 1970s.

${ }^{6}$ Batra and Khan (2005) carry out an analysis of comparative advantage for India and China in terms of the Balassa index.
} 
amounts of commodities, in different sub-segments of the sector. However, this issue is likely to be less crucial if the analysis is carried out at a sufficiently detailed level of disaggregation.

The source of our data is the World Trade Analyzer by Statistics Canada (see the Data Appendix). The data span the period 1985-2002. The LFI has been computed at a highly disaggregated level: 221 items from the three-digit Standard International Trade Classification (SITC). In order to reduce the impact of outliers and the impact of wide variation in exchange rates or prices, we use the 2-year average of the $L F I$.

Tables 3(a)-(c) report the top 15 and bottom 15 categories according to the $L F I$ for the years $1985 / 6,1995 / 6$, and 2001/2. The tables also report an indicator of the technological content of the sectors, computed according to OECD (2001, Annex A) and Khondaker (2005, Appendix 1). We have elected to concentrate on these periods because 1985/6 and 2001/2 are the beginning and the end of the time span in our analysis, and 1995/6 is a critical period since it already captures some of the transformations that took place in the aftermath of the implementation of reforms in the early 1990s. The tables show some interesting patterns in terms of the sectors that are represented in the top and bottom groups. First, in 1985/6, 'food and live animals' (category 0 ) featured prominently among the top 15 , with five product groups. By 1995/6, this number had fallen to three and, by 2001/2, only 'crustaceans and molluscs' and 'rice' were in the top 15. Second, Table 3(a) shows the importance of manufactured goods (categories 6 and 8) in 1985/6, with nine out of the top 15 product groups. By 2001/2 manufacturing dominated, with 11 out of the top 15 products (Table 3(c)). Third, India has only one category of crude material (category 2) in the top 15 (iron ore and concentrates), and its ranking has steadily declined. Fourth, in 1985/6 'chemicals and related products' (category 5) did not feature in the top 15 group. By 1995/6, 'medicinal and pharmaceutical products' appeared in the top 15, moving up to eighth position in 2001/2. Finally, regarding the dynamics of the various product groups, Tables $3(a)-(c)$ show a mixed picture. Some product groups maintained their position in the top 15 throughout the three periods examined. More importantly, a number of product groups have dropped out from the top group, while other industries have entered and remained in the top group. ${ }^{7}$

The analysis of the technological content of the product groups at the top and the bottom of the distribution is very revealing (see the Appendix for details on the classification of sectors according to their technology). In 1985/6 the top 15 groups only included categories with a low technological content. By contrast, the most import-dependent groups included numerous categories with a medium-high or high technological content (seven out of 15), and a further four with a medium-low technological content. This situation did not improve greatly, with nine out of 15 bottom-ranking groups being medium-high or high tech in 1995/6. By 2001/2 seven were in this category, of which six were high-tech sectors. Thus, sectors with a high or a medium-high technological content are dramatically over-represented among the most import-dependent sectors of the Indian economy. On the positive side, the high-tech category 'medical and pharmaceutical products' has become one of the industries in which India specializes most heavily.

\footnotetext{
${ }^{7}$ For instance, the categories 'rice', 'medicinal and pharmaceutical products', and 'jewellery, goldsmiths, and other articles of precious metals' did not feature in the top 15 in 1985/6, but entered the top group in 1995/6 and $2001 / 2$. Also, a number of products have dropped from the top 15 , especially in the category of 'food and live animals', but also in the manufactured goods category, such as 'leather and manufactures of leather'.
} 


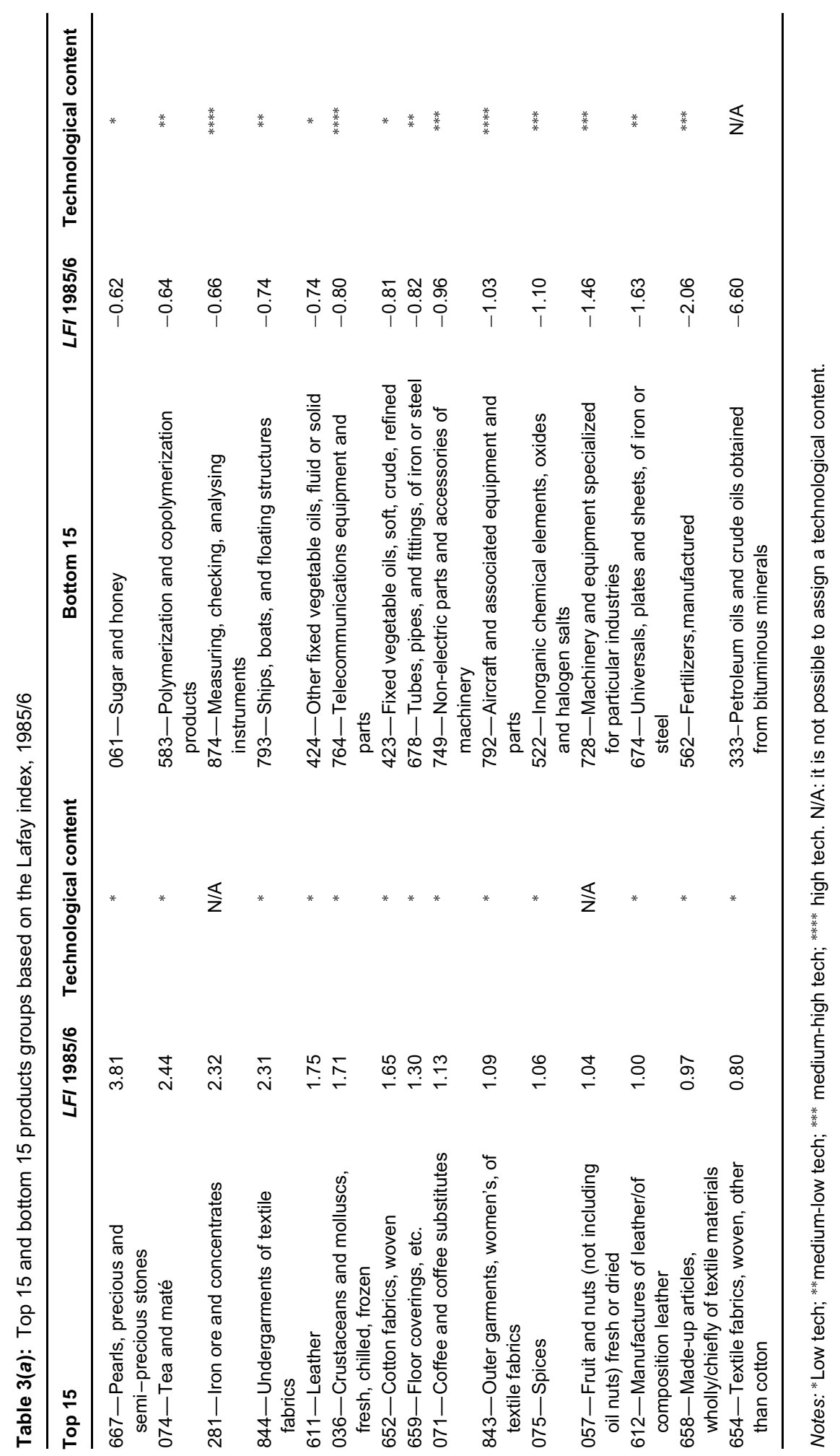




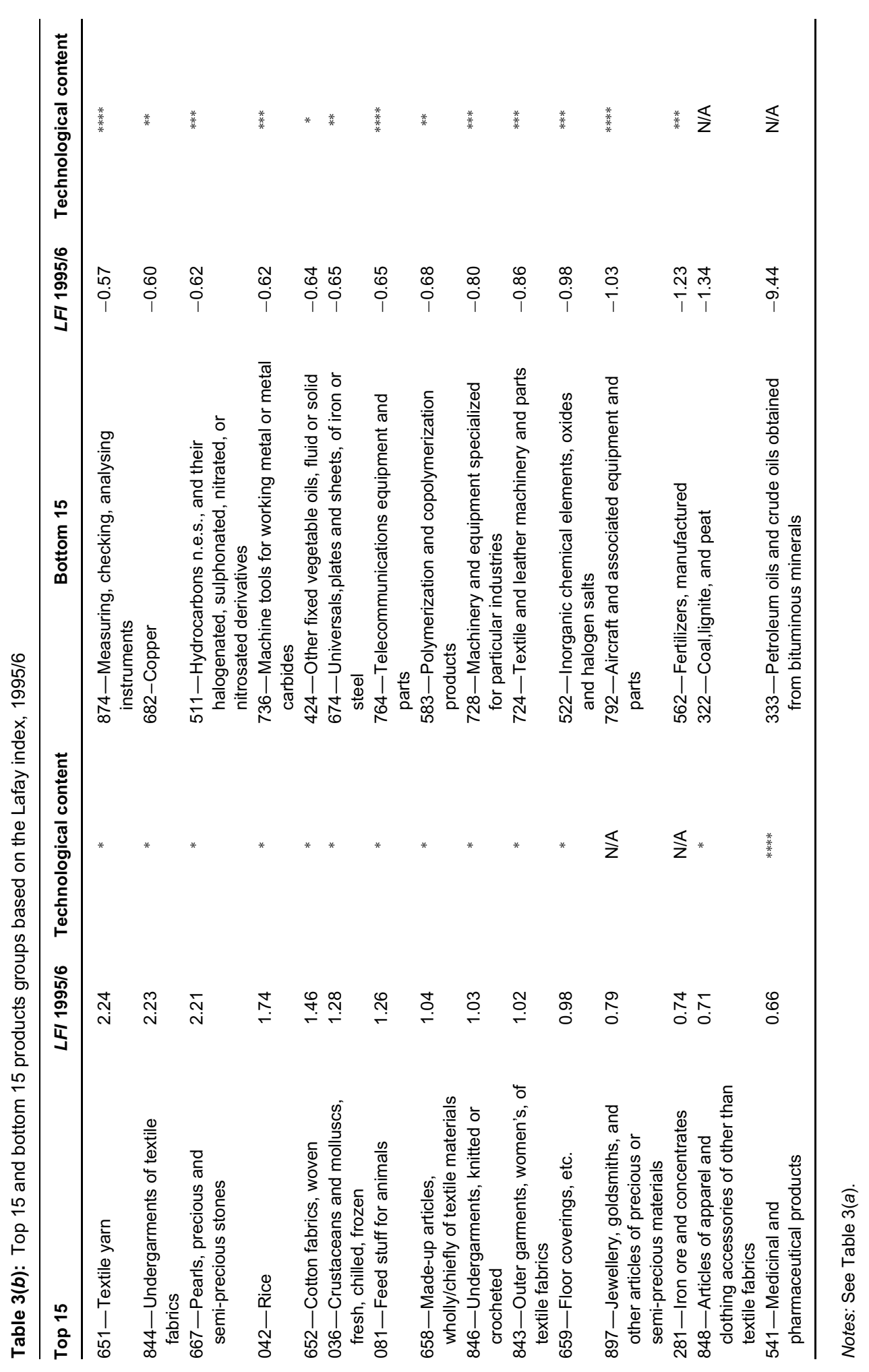




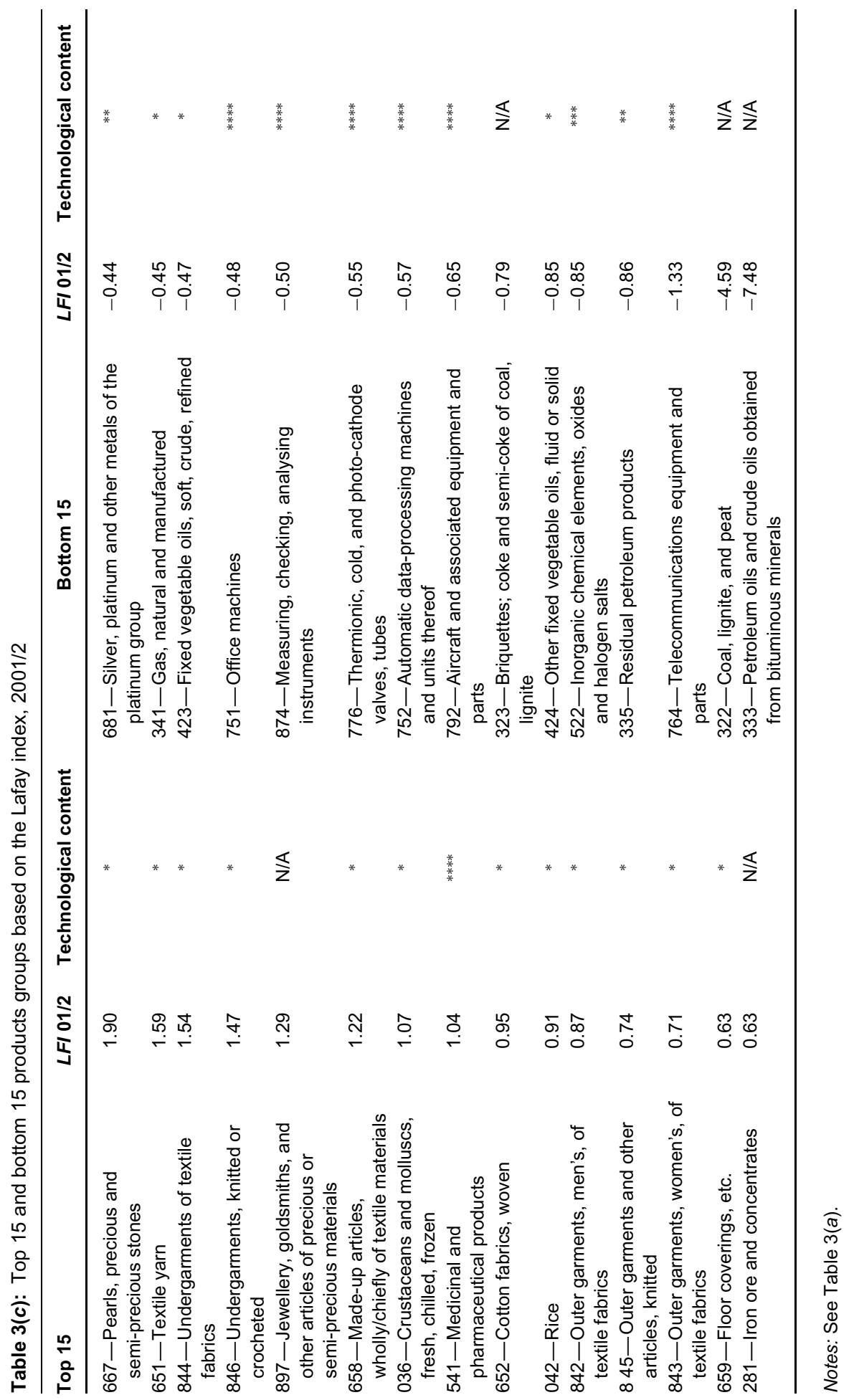


Table 4 shows the trade balance of each technological group. This is computed as the difference between exports and imports in each sector, divided by the total sum of exports and imports for India. While the trade surplus of low-tech sectors remains roughly constant over the sample period (but it did experience a large increase during the period 1995/6), the trade deficits of the remaining sectors display a notable improvement, which is particularly remarkable for medium-low- and medium-high-tech sectors.

Table 5 illustrates the changes over time in the average specialization index by technological content. In 1985/6, sectors with a low technological content were relatively specialized (the $L F I$ was positive at 0.28 ). By contrast, high-technology sectors were prevalent among the categories for which India was import-dependent. This was particularly true for medium-high and high technological content, where the index was -0.23 and -0.19 , respectively. During the sample period, there was a decline in the extent of trade specialization for low-tech groups (the LFI was equal to 0.19 in 2001/2) and an improvement for medium-low and medium-high groups (in the latter, the LFI increased sharply to -0.04), whereas the index has seen only a marginal improvement for the high-tech sectors $(-0.17)$. Together with the evidence from Table 4, these findings reinforce the perception that there was a shift in the sectoral contribution to foreign trade away from low-tech sectors and towards sectors with a medium technological content. ${ }^{8}$

Table 4: Trade balance by technological content

\begin{tabular}{lrrr}
\hline Technological content group & $\mathbf{1 9 8 5 / 6}$ & $\mathbf{1 9 9 5 / 6}$ & $\mathbf{2 0 0 1 / 2}$ \\
\hline Low tech & 0.138 & 0.193 & 0.144 \\
Medium-low tech & -0.096 & -0.036 & 0.002 \\
Medium-high tech & -0.148 & -0.084 & -0.022 \\
High tech & -0.067 & -0.045 & -0.044 \\
N/A & -0.065 & -0.092 & -0.105 \\
Total balance of trade & $-\mathbf{0 . 2 3 9}$ & $-\mathbf{0 . 0 6 6}$ & $-\mathbf{0 . 0 2 6}$ \\
\hline
\end{tabular}

Note: N/A: it is not possible to assign a technological content.

Table 5: Average Lafay index by technological content

\begin{tabular}{lcrrr}
\hline Technological content group & No. of observations & \multicolumn{3}{c}{ Average LFI } \\
\cline { 3 - 5 } & & $\mathbf{1 9 8 5 / 6}$ & $\mathbf{1 9 9 5 / 6}$ & $\mathbf{2 0 0 1 / 2}$ \\
\hline Low tech & 80 & 0.28 & 0.27 & 0.19 \\
Medium-low tech & 46 & -0.13 & -0.06 & 0.01 \\
Medium-high tech & 44 & -0.23 & -0.16 & -0.04 \\
High tech & 24 & -0.19 & -0.16 & -0.17 \\
N/A & 29 & -0.08 & -0.28 & -0.34 \\
\hline
\end{tabular}

Note: N/A: it is not possible to assign a technological content.

\footnotetext{
${ }^{8}$ An important proviso to the previous analysis is that one must be cautious in interpreting trade flow data as providing evidence of trade specialization, when barriers to trade are present. Hence, it is highly debatable whether the early figures from the mid-1980s can provide information on the pattern of comparative advantage. However, the figures from the more recent periods arguably offer a closer picture of the underlying structure of sectoral comparative advantage, following the removal of barriers to trade during the 1990s.
} 
Figure 3: Lafay index, 2001/2 against 1985/6

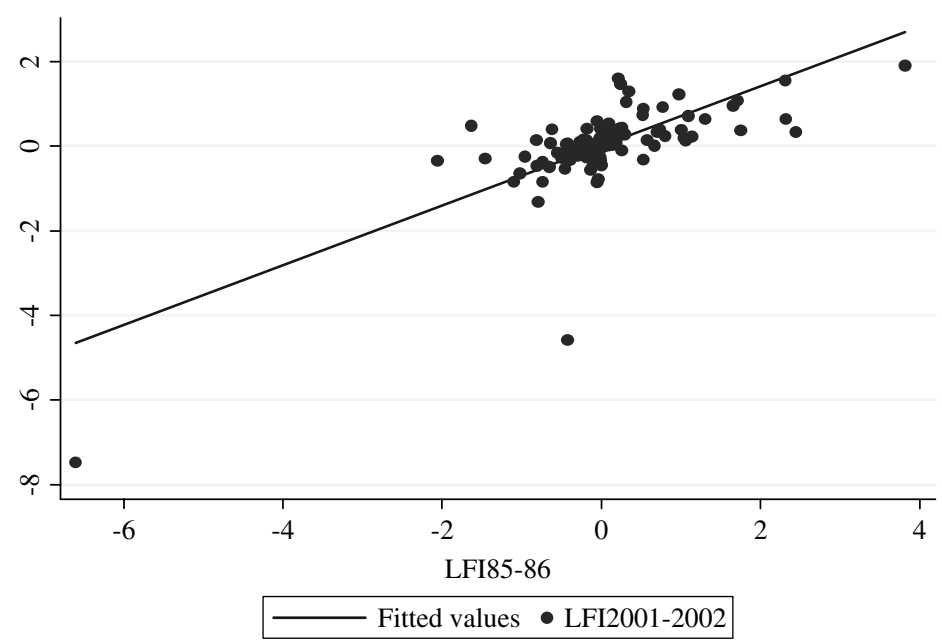

\section{The changing pattern of specialization}

To assess whether India became more specialized in the period under study, we first run the following simple OLS regression:

$$
\operatorname{LFI}_{j}^{2001-2002}=\alpha+\beta \operatorname{LFI}_{j}^{1985-1986}+\varepsilon \quad j=1, \ldots, 221
$$

where $L F I^{2001-2002}$ and $L F I^{1985-1986}$ are the Lafay indices in the final and initial periods of our sample, respectively. Since variables on both sides of the equation have a zero mean, the estimate of $\alpha$ should also have a zero value, whereas the value of $\beta$ would capture the changes over time in the pattern of specialization. If $\beta$ is greater than one then the degree to which India has specialized or not specialized in certain industries has increased; if $\beta$ is less than one, the existing pattern of specialization in particular industries has lessened. If $\beta$ is 0 then there is no relation between the pattern of specialization in the two periods.

Figure 3 presents the scatter diagram with a fitted regression line, while Table 6 reports the regression results. As can be seen from this table, the estimated coefficient is 0.70 and highly significant. The table also shows that we can reject both the null hypothesis that the slope is equal to zero (at the 1 per cent level) as well as the null hypothesis that the slope is equal to unity (also at the 1 per cent level).

The scatter diagram points to the possibility that these results might be influenced by the existence of two potential outliers. To check the robustness of our findings, the equation is re-estimated after dropping the outliers (these are 'petroleum oils and crude oils' and 'coal, lignite, and peat'). The estimated coefficient declines in value from 0.70 to 0.42 and we can again reject both the null that the slope is equal to zero and the null that the slope is equal to unity at the 1 per cent level. In any case, both the estimated results and the scatter diagram suggest that the estimated regression line is positive and lies below the $45^{\circ}$ line. This indicates that, although the LFI has shown some improvement for items with initial low values and 
Table 6: OLS regression of Lafay index in 2001/2 against Lafay index in $1985 / 6$

\begin{tabular}{lcc}
\hline & Full sample & Without the outliers \\
\hline$\alpha$ & $0.000(0.032)$ & $0.041(0.019)$ \\
$\beta$ & $0.705(0.044)$ & $0.422(0.053)$ \\
No. of observations & 221 & 219 \\
Ho: $\beta=0$ & Rejected at the $1 \%$ level & Rejected at the $1 \%$ level \\
Ho: $\beta=1$ & Rejected at the 1\% level & Rejected at the 1\% level \\
\hline
\end{tabular}

Notes: Estimated equation: $L F I^{2001-2}=\alpha+\beta L F I^{1985-6}+\varepsilon$. Standard errors in brackets.

Table 7: Transition matrix (transition probabilities from 1985/6 to 2001/2)

\begin{tabular}{lcccc}
\hline & Quartile I & Quartile II & Quartile III & Quartile IV \\
\hline Quartile I & 0.527 & 0.163 & 0.054 & 0.254 \\
Quartile II & 0.163 & 0.400 & 0.290 & 0.145 \\
Quartile III & 0.054 & 0.109 & 0.709 & 0.127 \\
Quartile IV & 0.017 & 0.017 & 0.089 & 0.875 \\
\hline
\end{tabular}

Notes: $M^{1}=(K-$ trace (transition matrix $\left.)\right) /(K-1)=0.496$. $M^{2}=1-\operatorname{det}($ transition matrix) $=0.901$.

some retreat for those with initial high values, on average the specialization pattern remained the same (see Caselli and Zaghini (2005) for a similar interpretation).

A more precise analysis of the evolution of the $L F I$ distribution over the sample period can be obtained by using transition probabilities (as in Redding, 2002). These measure the probabilities that individual sectors become more or less specialized over time, as a function of their initial degree of specialization. Sectors have been grouped into quartiles on the basis of their initial specialization. Quartile I includes those sectors with the lowest value of the LFI in 1985/6, and quartile IV contains the sectors with the highest initial values of the index. Table 7 is a four-by-four Markov transition matrix, showing the estimated transition probabilities from $1985 / 6$ to $2001 / 2$. Each cell $(i, j)$ describes the probability that an item in the relative specialization group $i$ at time $t$ moves to group $j$ in time $t+1$. Thus, the elements of the transition matrices represent the probabilities of moving from one quartile to another, conditional on the initial level of specialization. For instance, the first row measures the probability of a product starting from the first quartile remaining in the first quartile or transiting into the second, the third, or the fourth quartile.

As can be seen from Table 7, the largest values of the transition probabilities occur along the main diagonal. This implies a certain degree of persistence in specialization. However, the highest values of the diagonal elements correspond to quartiles III and IV. It might be relatively easier for a specialized sector to remain specialized than it would be for a previously import-dependent sector to become a sector in which India specializes: once India has achieved specialization in a certain product, it is likely to maintain this specialization over time. However, the largest off-diagonal element for the lowest quartile corresponds to quartile IV, which suggests that a number of sectors for which India was relatively import dependent at the beginning of the period had 
experienced a remarkable improvement in specialization by the beginning of the last decade.

A measure of mobility across specialization levels is provided by the indicators $M^{1}$ and $M^{2}$, originally proposed by Shorrocks (1978). The indicator $M^{1}$ captures the relative magnitude of the diagonal and off-diagonal elements by calculating the trace of the transition matrix, whereas $M^{2}$ is based on the determinant of the transition matrix. ${ }^{9}$ High values of the indices imply a large degree of mobility across specialization groups. These indices allow us to compare the mobility across specialization groups in India with studies that analyse trade specialization in other countries. Zaghini (2005) computes the two mobility indices for a group of new EU member states. ${ }^{10}$ Comparing our results with those of the new EU member states can be informative since, like India, in recent years these states have also experienced structural economic and institutional transformations. Comparing our findings with Zaghini's results, we find that the mobility indices for India are larger in value than any other country in his sample. The estimated value for $M^{1}$ for India is 0.496 and the value for $M^{2}$ is 0.901 . By comparison, the highest values of $M^{1}$ and $M^{2}$ in Zaghini's sample over the period 1993-2001 are 0.411 and 0.815, respectively, and are obtained for Latvia. These findings could indicate a relatively high degree of dynamism in the Indian economy, even when compared to economies that experienced a radical process of transition.

There is, therefore, evidence of changes in the global pattern of specialization, with import-dependent sectors gradually becoming more specialized over time.

\section{Specialization and world demand}

The results in the previous section are suggestive of high mobility in the specialization pattern, especially towards an increase in specialization. But have these changes in specialization been towards the most dynamic product groups? An answer to this question can be obtained by comparing the evolution over time of the specialization index against world demand for the product items. A specialization model can be labelled as 'efficient' when the country gains comparative specialization in product groups for which global demand has grown the fastest (Zaghini, 2005). On the other hand, a specialization model is labelled 'inefficient' when the country gains specialization advantage in products groups in which global demand growth has been in decline.

An effective way to check for the efficiency of the specialization model is to examine the cumulative distribution of the Lafay index ranked according to the average growth rates of world imports for the period 1986-2002. The graph starts with the Lafay index of the item with the slowest growth and must end at zero by construction for the item with the fastest growth. If India systematically specialized in products which showed slow growth on a world scale, then the beginning of the distribution would show positive values. If India was highly import dependent on slowly growing products, then the graph would show negative values initially.

Figure 4 plots the cumulative distribution of the Lafay index for the years 1985/6 and 2001/2 against world import growth. These graphs yield some very interesting results. The

\footnotetext{
${ }^{9}$ Table 7 reports the formulae and the values of these indices.

${ }^{10}$ These are: Czech Republic, Estonia, Hungary, Latvia, Lithuania, Poland, Slovak Republic, Slovenia, Cyprus, and Malta.
} 
pattern of specialization has improved over the period in the sense that, on average, India has not specialized in sectors that have experienced the lowest growth in world demand. On the other hand, India did improve its trade specialization in the very product groups that have witnessed the highest global growth. The average value of the $L F I$ for the slowest-growth sectors was -0.097 in 1985/6, and had decreased to -0.245 in 2001/2 (Table 8). Thus, India has not specialized in the sectors whose world demand grew more slowly. By contrast, the index has improved for the medium growth, medium-high growth, and fastest growth sectors. The values of the $L F I$ for the last two categories improved from 0.095 to 0.125 and from 0.022 to 0.078 , respectively. Hence, it would appear that India is improving its pattern of specialization in the very sectors that grew fastest in terms of world demand.

In order to illustrate the profile of specialization of Indian sectors in relation to world demand, Figure 4 also indicates the position of the ten sectors in which India showed the highest degree of specialization in 2001/2. These correspond to the items on the cumulated Lafay curve which exhibited the largest positive jumps. It can be seen that most sectors can be found in the upper half of the distribution, which contains the medium-high and fastest

Figure 4: The cumulated Lafay index: items ordered by world import growth over the period 1985/6 to $2001 / 2$

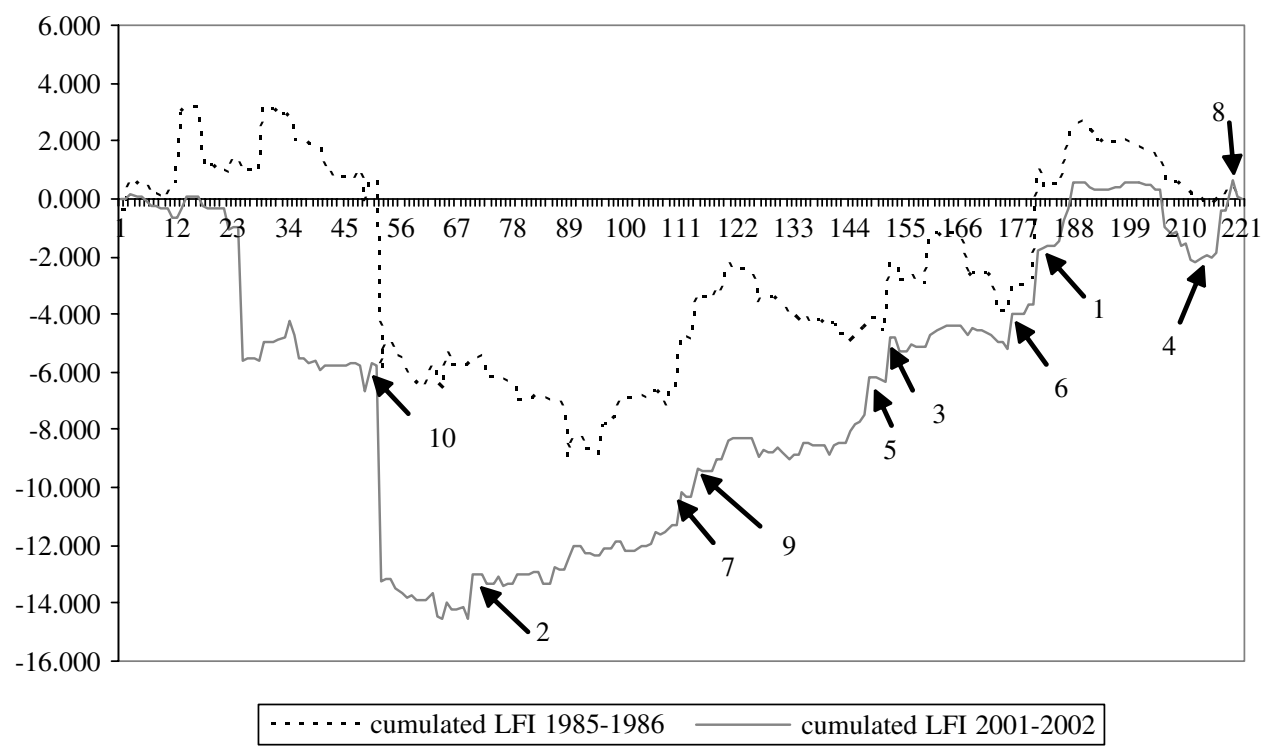

Notes:

1. Pearls, precious and semi-precious stones

2. Textile yarn

3. Undergarments of textile fabrics

4. Undergarments, knitted or crocheted

5. Jewellery, goldsmiths, and other articles of precious or semi-precious materials

6. Made-up articles, wholly/chiefly of textile materials

7. Crustaceans and molluscs, fresh, chilled, frozen

8. Medicinal and pharmaceutical products

9. Cotton fabrics, woven

10. Rice 
Table 8: Average Lafay index by world demand, $1985 / 6$ and $2001 / 2$

\begin{tabular}{lcc}
\hline Groups & Average LFI 1985/6 & Average LFI 2001/2 \\
\hline Slowest growth (mean growth: 1.80\%) & -0.097 & -0.245 \\
Medium growth (mean growth: 5.25\%) & -0.020 & 0.040 \\
Medium-high growth (mean growth: 7.40\%) & 0.095 & 0.125 \\
Fastest growth (mean growth: 10.00\%) & 0.022 & 0.078 \\
\hline
\end{tabular}

growth groups. This confirms that the Indian manufacturing sector tends to present a pattern of specialization that is consistent with the dynamics of world demand.

\section{Conclusions}

In 1999, the late Sanjaya Lall argued that 'a technology-intensive structure is desirable for a country with a substantial industrial base. India has such a base, but its export structure is dominated by low-technology products and concentrated in slow growing market segments' (Lall, 1999, p. 1784). Recent enthusiasm for the performance of some high-tech service sectors has generated great optimism for India's trade potential and for the possible impact on the continued growth prospects of the country. Our analysis of trade flows over the last couple of decades confirms Lall's critical observations on the modest technological content of Indian exports. Low-technology sectors dominate the categories for which India exhibits the largest degree of trade specialization, while high-technology sectors are over-represented among the categories for which India appears to be import-dependent.

However, we find that India did experience an improvement in the degree of specialization in some of the most dynamic sectors of world trade. Its index of specialization has increased, on average, for the sectors that have grown the fastest since the mid1980s. Thus, the impact of the relationship between India's trade potential and growth needs cautious examination. The technological content of India's best-performing sectors remains dominated by traditional activities. The few but significant exceptions, such as 'medicinal and pharmaceutical products', could signal for a shift towards a more widespread adoption of advanced technologies. This will be especially true if India succeeds in realizing its potential for original innovation, already confirmed by the number of patents that are earned by the Indian subsidiaries of multinational firms (The Economist, 2004) and by such imaginative projects as the 'one lakh' car (The Economist, 2006), which would be by far the cheapest car currently produced in the world.

\section{Data Appendix}

(i) The Lafay index

The main source of the data used for the construction of the Lafay index is the 'World Trade Analyzer 1985-2002' (WTA), Statistics Canada (CD-ROM, November 2004). The classification of the sectors is based on SITC-2. The total value of imports for sector 3 (fuels) has been obtained from the World Development Indicators 2006 (World Bank, 2006), since the WTA data for this sector exhibited a large difference from the data from 
other sources. In particular, the WTA data showed a sharp reduction of fuel imports during the 1990s, with a consequent underestimation of total imports. The figures for two- and three-digit sectors within sector 3 have been computed by using the shares from WTA.

(ii) Index of technological content

The taxonomy of technological content for sectors follows the OECD classification presented in 'OECD Science, Technology and Industry Scoreboard 2001 - Towards a Knowledge-based Economy, Annex A. Classification of Manufacturing Industries Based on Technology'. The methodology uses two indicators of technology intensity: (i) R\&D expenditures divided by production, and (ii) R\&D expenditures divided by value added. The classification of the sectors is based on the analysis of R\&D expenditure and output in 12 OECD countries ${ }^{11}$ for the period 1991-9. Manufacturing industries are classified as low-technology, medium-low-technology, medium-high-technology, and high-technology groups. Sectors included in higher categories have a higher intensity for both indicators than sectors included in lower categories. Some sectors belonging to mining or agricultural industries present no expenditure in $R \& D$ and are classified as N/A. OECD makes use of the International Standard Industrial Classification (ISIC-3). In order to convert the figures from ISIC-3 to SITC-2 we have made use of the conversion table in Khondaker (2005, Appendix 1).

\section{References}

Ahluwalia, M. S. (2002), 'Economic Reforms in India since 1991: Has Gradualism Worked?', Journal of Economic Perspectives, 16(3), Summer, 67-88.

Alcalà, F., and Ciccone, A. (2004), 'Trade and Productivity', Quarterly Journal of Economics, 119(2), $613-46$.

Arora, A., and Gambardella, A. (2004), 'The Globalization of the Software Industry: Perspectives and Opportunities for Developed and Developing Countries', NBER Working Paper No. 10538.

Balassa, B. (1965), 'Trade Liberalization and "Revealed" Comparative Advantage', The Manchester School of Economic and Social Studies, 32(2), 99-123.

Banerjee, A. V. (2006), 'The Paradox of Indian Growth: A Comment on Kochhar et al.', Journal of Monetary Economics, 53(5), 1021-6.

Batra, A., and Khan, Z. (2005), 'Revealed Comparative Advantage: An Analysis for India and China', ICRIER Working Paper No. 168, Indian Council for Research on International Economic Relations.

Caselli, P., and Zaghini, A. (2005), 'International Specialization Models in Latin America: The Case of Argentina', Banca d'Italia, Discussion Paper No. 558.

Cerra, V., Rivera, S. A., and Saxena, S. C. (2005), 'Crouching Tiger, Hidden Dragon: What are the Consequences of China's WTO Entry for India's Trade?', IMF Working Paper No. 05/101, Washington, DC, International Monetary Fund.

Chauvin, S., and Lemoine, F. (2003), 'India Bets on Technology Niches', Centre d'Etudes Prospectives et d'Informations Internationales, Working Paper No. 221, March.

Commander, S., Chanda, R., Kangasniemi, M., and Winters, A. (2004), 'Must Skilled Migration Be a Brain Drain? Evidence from the Indian Software Industry', IZA Discussion Paper No. 1422, December.

Das, D. K. (2003), 'Quantifying Trade Barriers: Has Trade Protection Declined Substantially in Indian Manufacturing?', ICRIER Working Paper No. 105, Indian Council for Research on International Economic Relations.

\footnotetext{
${ }^{11}$ Canada, Denmark, Finland, France, Germany, Ireland, Italy, Japan, Spain, Sweden, the United Kingdom, and the United States.
} 
Dasgupta, S., and Singh, A. (2005), 'Will Services Be the New Engine of Economic Growth in India?', Centre for Business Research, University of Cambridge, Working Paper No. 310.

- _ (2006), 'Manufacturing, Services and Premature De-industrialisation in Developing Countries: A Kaldorian Empirical Analysis', Centre for Business Research, University of Cambridge, Working Paper No. 327.

DeLong, B. (2004), 'India since Independence: An Analytic Growth Narrative', ch. 7 in D. Rodrik (ed.), In Search of Prosperity, Princeton, NJ, Princeton University Press: 184-204.

Grossman, G., and Helpman, E. (1991), Innovation and Growth in the Global Economy, Cambridge, MA, MIT Press.

Kaldor, N. (1967), Strategic Factors in Economic Development, Ithaca, NY, New York State School of Industrial and Labor Relations, Cornell University.

Khondaker, J. A. (2005), 'Technology Intensity of Canadian Exports: A Comparative Investigation (III-G)', International Trade Division, Statistics Canada.

Kochhar, K., Kumar, U., Rajan, R., Subramanian, A., and Tokatlidis, I. (2006), 'India's Pattern of Development: What Happened, What Follows?', Journal of Monetary Economics, 53(5), 981-1019.

Kohli, A. (2006a), 'Politics of Economic Growth in India, 1980-2005. Part I: The 1980s', Economic and Political Weekly, 1 April, 1251-9.

- (2006b), 'Politics of Economic Growth in India, 1980-2005. Part II: The 1990s and Beyond', Economic and Political Weekly, 8 April, 1361-70.

Krishna, P., and Mitra, D. (1998), 'Trade Liberalisation, Market Discipline and Productivity Growth: New Evidence from India', Journal of Development Economics, 56(2), 447-62.

Lafay, G. (1992), 'The Measurement of Revealed Comparative Advantage', in M. G. Dagenais and P. A. Muet (eds), International Trade Modelling, London, Chapman \& Hall.

Lall, S. (1992), 'Technological Capabilities and Industrialization', World Development, 20(2), 165-86.

- (1999), 'India's Manufactured Exports: Comparative Structure and Prospects', World Development, 27(10), 1769-86.

NASSCOM (2006), Strategic Review 2006. The IT Industry in India, New Delhi, National Association of Software and Service Companies.

OECD (2001), OECD Science, Technology and Industry Scoreboard 2001, Paris, Organization for Economic Cooperation and Development.

Panagariya, A. (2004), 'India in the 1980s and 1990s: A Triumph of Reforms', International Monetary Fund, Working Paper No. 04/03, March.

Patibandla, M., and Petersen, B. (2002), 'Role of Transnational Corporations in the Evolution of a High-tech Industry: The Case of India's Software Industry', World Development, 30(9), 1561-77.

Redding, S. (2002), 'Specialization Dynamics', Journal of International Economics, 58(2), 299-334.

Rodrik, D., and Subramanian, A. (2004), 'From "Hindu Growth" to Productivity Surge: The Mystery of the Indian Growth Transition', NBER Working Paper No. 10376, March.

Rowthorn, R. (2006), 'The Renaissance of China and India: Implications for the Advanced Economies', University of Cambridge, mimeo.

Saxenian, A. (2002), 'Transnational Communities and the Evolution of Global Production Networks: The Cases of Taiwan, China and India', Industry and Innovation, Special Issue on Global Production, 9(3), $183-202$.

Schiff, J. (2005), 'India Going Global: Its Expanding Role in the World Economy', International Monetary Fund, mimeo.

Sharma, K. (2000), 'Export Growth In India: Has FDI Played A Role?', Economic Growth Center, Yale University, Discussion Paper No. 816, July.

Shorrocks, A. F. (1978), 'The Measurement of Mobility', Econometrica, 46(5), 1013-24.

Statistics Canada (2004), World Trade Analyzer, 1985-2002, Statistics Canada.

The Economist (2004), 'Innovative India: Please Don't Call It Outsourcing', 1 April.

- (2006), 'A Different Route: While China's Carmakers Copy, India's Are Inventing', 13 December.

- (2007), 'India on Fire', 1 February.

Topalova, P. (2004), 'Trade Liberalization and Firm Productivity: The Case of India', International Monetary Fund, Working Paper No. 04/28.

Tucci, A. (2005), 'Trade, Foreign Networks and Performance: A Firm-level Analysis for India', Centro Studi Luca D'Agliano, Development Studies Working Paper No. 199, March. 
UNCTAD (2005), UNCTAD Handbook of Statistics, Geneva, United Nations.

World Bank (2006), World Development Indicators, Washington, DC, World Bank.

WTO (2001), International Trade Statistics, Geneva, World Trade Organization.

Young, A. (1991), 'Learning-by-Doing and the Dynamic Effects of International Trade', Quarterly Journal of Economics, 106(2), 396-405.

Zaghini, A. (2005), 'Evolution of Trade Patterns in the New EU Member States', Economics of Transition, 13(4), 629-58. 